\title{
Autoecologia das espécies florestais em regime de plantio de enriquecimento em linha na floresta primária da Amazônia Central
}

\author{
Akira TANAKA ${ }^{1}$, Gil VIEIRA²
}

RESUMO

A autoecologia das três espécies florestais em linhas de enriquecimento foi avaliada junto com o monitoramento do microclima e fertilidade do solo na floresta primária de terra-firme da Amazônia brasileira. A área situa-se no município de Novo Aripuanã Amazonas - Brasil ( $\left(5^{\circ} 18^{\prime} \mathrm{S}, 60^{\circ} 04^{\prime} \mathrm{W}\right.$.). Nas três diferentes larguras de linhas $(3,5 \mathrm{e} 7 \mathrm{~m})$ foram monitoradas os parâmetros de radiação com fotografias hemisféricas e sensor RFA. As linhas de 5 e $7 \mathrm{~m}$ classificam-se como grande abertura de dossel (19,77-20,78\%), a de $3 \mathrm{~m}$ mostrou maior variação na radiação RFA. Quanto à análise química do solo observou-se, uma redução significativa de Ke Ca em relação ao aumento das larguras das linhas. Também foram monitorados os crescimentos em altura e diâmetro, índice de ganho foliar e o teor de clorofila nas plântulas das três espécies estidadas: Astronium lecointei Ducke, Cordia goeldiana Huber e Scleronema micranthum Ducke. Todas espécies sofreram devido à alta radiação e ao estresse hídrico. Astronium lecointei apresentou uma maior resistência tanto durante forte seca, como também ao excesso de chuva. Scleronema micranthum apresentou diferenças de crescimento entre linhas, principalmente na estação chuvosa. Beneficiou-se positivamente com a radiação direta nas linhas largas de enriquecimento. As duas apresentaram alta amplitude de nicho entre tolerante à sombra a intermediária. Já C.goeldiana apresentou maior variação em seu crescimento (CV: Cordia goeldiana: 113> Astronium lecointei: 60,6> Scleronema micranthum: 59,7). A largura de linha de $5 \mathrm{~m}$ na floresta primária de terra-firme foi suficiente para estabelecimento de espécies tolerante à sombra e intermediária.

\section{PALAVRAS-CHAVE}

Radiação, fotografia hemisférica, plântula, linha de enriquecimento, Amazônia.

\section{Autoecology of forest species in line plannting enrichment system in primary forest in Central Amazonia.}

\begin{abstract}
In this study, autoecological traits of three Amazonian terra-firme tree species grown in enrichment plantation lines were evaluated. The microclimatological parameters also were assessed in these lines. The study site is located in Novo Aripuanã, Amazonas State, Brazil (5 $5^{\circ} 18^{\prime}$, $\left.60^{\circ} 04^{\prime} \mathrm{W}\right)$. Light condition in the three width lines $(3,5$ and $7 \mathrm{~m})$ were assessed using hemispherical photographs and PAR sensor focusing radiation parameters. Although lines of 5 and $7 m$ widths can be classified as large canopy opening (19,77-20,78\%), lines of $3 m$ represented major PAR variation. For soil chemical analysis, a significant reduction of K ans Ca was observed. Three tree species seedlings, Astronium lecointei Ducke, Cordia goeldiana Huber and Scleronema micranthum Ducke were set in the enrichment plantation lines. The relative growth rate (stem diameter +height) and chlorophyll contents were monitored in these plants. Allspecies were subjected to high direct and diffuse radiation, low levels of nutrients and water stress. Astronium lecointei Ducke showed high drought resistance. Scleronema micranthum in the rainy season also benefited in the wider enrichment lines, showing positive responses to direct radiation. These two species showed features of intermediate to shade tolerant species (broad niche) when growth patterns were compared. On the other hand, C.goeldiana showed greater growth fluctuation than others (VC: Cordia goeldiana: 113> Astronium lecointei: 60, 6> Scleronema micranthum: 59,7). Lines with five meters widths of primary terra-firme forests should be sufficient to establish shade tolerant and intermediate species.
\end{abstract}

KEY WORDS

Radiation, hemispherical photograph, tree-seedling, enrichment line, Amazônia.

${ }^{1}$ Bolsista do CNPq, Instituto Nacional de Pesquisas da Amazônia (INPA), Coordenação de Pesquisas da Ecologia (CPEC), 69011-970 Manaus,AM, Brasil

${ }^{2}$ Instituto Nacional de Pesquisas da Amazônia (INPA), Coordenação de Pesquisas da Silviculturas Tropicais (CPST), 69011-970 Manaus,AM, Brasil 


\section{INTRODUÇÃO}

Há diversos estudos sobre comportamento e estabelecimento de plântulas em visão ecofisiológica das espécies florestais (Grubb, 1977; Chazdon \& Pearcy, 1986; Chazdon, 1988; Brown, 1993; Ramos \& Grace, 1990; Riddoch et al., 1991; Bazzaz \& Wayne, 1994; Wayne \& Bazzaz, 1993; Vieira, 1987; 1996; Engelbrecht et al., 2002). Porém estudos com nichos regenerativos das espécies considerando os aspectos do ambiente físico da floresta tropical em clareiras são ainda bastante escassos principalmente na região amazônica (Bassini, 1994; Rego, 1995; Useche, 2003). Os ambientes artificiais criados a partir das técnicas de manejo florestal ou silvicultura, como a abertura das clareiras em forma de linhas abertas em sistema de enriquecimento tem sido testado há muito tempo (Aubrèville, 1938; Catinot, 1965). Porém, nestes estudos não houve um monitoramento preciso das condições microclimáticas, nem das mudanças fisiológicas das espécies conforme o tamanho da abertura (largura e extensão das linhas).

Neste cenário, este estudo tem como objetivado para o entendimento dos aspectos ecofisiológicos de três espécies florestais de terra-firme em função das variações microclimáticas observadas nas linhas de enriquecimento, tais como: regime de radiação solar modificado pela abertura das linhas. Os experimentos para caracterização da autoecologia das espécies foram montados para testar principalmente o fator lumínico, como radiação fotossintéticamente ativa (RFA). A observação da radiação neste trabalho é distinguida em dois parâmetros; Fator Direto e Indireto de Sítio (FDS / FIS) sendo fraçōes de radiação direta e indireta que interceptam em um certo ponto no subbosque em relação ao valor de radiação recebida acima do dossel. Esta variação pode ser influenciada pela posição na estrutura vertical da floresta, estágio successional e estação do ano.

De um modo geral, a condição microclimática das clareiras é função do tamanho e orientação geográfica das mesmas (Schulz, 1960; Denslow, 1980; Chazdon \& Fetcher, 1984), sendo que estas diferenças afetam a oferta de recursos primários para o crescimento das plântulas (Brown, 1993; Bullock, 2000). Em ambiente de clareira observa-se também uma heterogeneidade de concentração de nutrientes no solo, sendo causada pela decomposição de folhas, troncos e galhos caídos. Ocorre ainda uma alteração quantitativa dos nutrientes pela lixiviação, alta radiação e temperatura excessiva (Brandani et al., 1988; Yano, 1998). Esta oferta diferenciada de recursos influencia muito no estabelecimento das plântulas (Chazdon, 1988), refletindo na composição florística e crescimento das plantas (Pearcy et al., 1989; Vieira, 1996; Yano, 1998).

$\mathrm{O}$ aproveitamento da radiação pelas plantas é dependente da amplitude dos comprimentos de ondas assimiláveis pelos vegetais, a qual é variável de acordo com as espécies. Portanto esta amplitude é um importante fator para a classificação das espécies. A dicotomia de grupos ecológicos como espécies exigentes à luz (heliófilas) e tolerantes à sombra (umbrófila) é ambígua, e deve existir um gradiente de exigências lumínicas que variam durante todo o ciclo de vida das espécies e é pouco conhecido na Amazônia (Vieira, 1996). A hipótese do presente trabalho é que espécies não clímax mostram sua maior amplitude de nicho regenerativo do que espécies clímax, possuindo estratégia peculiar na fase de estabelecimento de plântulas. Portanto, procura-se a diferença de plasticidade fisiológica das plântulas, através de determinaçẫo de conteúdo de clorofila foliar em diferentes larguras das linhas de enriquecimento, supondo que a luz deve variar conforme o grau de abertura no dossel (Boardman, 1977; Björkman, 1981; Bazzaz \& Carlson, 1982; Givnish, 1987; Press et al,. 1996). Estes conhecimentos sobre as especies arbóreas tropicais são de suma importância na silvicultura e manejo florestal na Amazônia.

\section{MATERIAL E MÉTODOS}

\section{DESCRIÇÃO DA ÁREA}

Os experimentos foram instalados em floresta primária de terra-firme no município de Novo Aripuanã, Amazonas ( $5^{\circ} 18^{\prime}$ S/ $60^{\circ} 04^{\prime}$ W), em talhão de nove hectares na floresta continua entre os rios Madeira e Acari. A vegetação local pertence à Floresta Tropical Densa de terras de baixo platô, e Floresta Tropical Densa com emergentes. A altura do povoamento é aproximadamente 30 m (Radambrasil, 1978). Na classificação de Köppen, o clima é Af, a precipitação total anual registrada é $2.750 \mathrm{~mm}$, temperatura média anual $26^{\circ} \mathrm{C}$ e umidade relativa do ar média anual 85\% (Radambrasil, 1978). O ano de 1997 foi considerado um ano atípico, fortemente influenciado pelo fenômeno El Niño, sendo que para a precipitação anual, registrou-se $1.941 \mathrm{~mm}$ (INPE, 1997).

\section{DESENHO EXPERIMENTAL}

As espécies utilizadas neste estudo são Astroniun lecointei Ducke (ANACARDIACEAE), Scleronema micranthum Ducke (BOMBACACEAE) e Cordia goeldiana Huber (BORAGINACEAE), espécies amazonicas de valor econômico, sendo utilizadas para diversas utilidades (Araújo, 1970; Loureiro et al., 1977; Silva \& Canto, 1994).

O experimento foi instalado entre três níveis de larguras das linhas abertas na floresta primária, sendo as larguras de $3 \mathrm{~m}, 5 \mathrm{~m}$ e $7 \mathrm{~m}$. Cada linha tem $900 \mathrm{~m}$ de comprimento sendo instalado em sentido leste-oeste. As mudas de A. lecointei e C.goeldiana foram feitas com substrato composto por $80 \%$ de terra-preta e $20 \%$ de areia fina, sem aplicação de adubo. A terra-preta foi encontrada na proximidade de local de experimento em forma natural que ocorre como mancha na floresta. Para S. micranthum foi utilizado semeada direta nas covas. Foram semeadas 100 sementes de $S$. micranthum em fevereiro de 1997, 100 mudas de A. lecointei e C. goeldiana foram plantadas em abril de 1997, após o preparo em saco polietileno, no centro da linha aberta com espaçamento de $3 \mathrm{~m}$. 
A média dos valores de crescimento e concentração de clorofila das espécies por largura de linha foi comparada por One-Way Anova. Para comparação dos tratamentos, diferentes larguras das linhas, aplicou-se o teste de Tukey para crescimento, teste de Duncan para teor de clorofila, ambos em $95 \%$ de probabilidade. Somente o resultado da análise do solo foi comparado por Duncan e Scheffé na mesma probabilidade.

Os parâmetros de crescimentos das plântulas para os fatores de ambiente lumínico e o teor de clorofila foram avaliados por análise de regressão simples para verificar a existência de relação entre plântulas - ambientes.

\section{RADIAÇÃO MEDIDA E ESTIMADA - FOTOGRAFIAS HEMISFERICAS}

A Radiação Fotossintéticamente Ativa (RFA) instantânea, media de cada 15 segundos, foi obtido com light meter-Licor Li250 com sensor esférico, Quantum Sensor-Licor 190SA. A medição foi realizada entre 11:00-13:00 horas nos dias de céu claro (aberto) na estação seca para obter os picos máximos de radiação. Para caracterização do ambiente de radiação, tais como: 1) abertura do dossel florestal (\% de abertura), 2) RFA direta, 2) RFA difusa, 3) Fator Direto de Sítio (FDS), 4) Fator Indireto de Sítio (FIS) através das fotografias hemisféricas. Para obtenção da imagem foi utilizada lente Olho de peixe Nikkor $8 \mathrm{~mm}$. As fotografias adquiridas foram interpretadas pelo programa WINPHOT VERSION 4.0 (ter Steege 1994). A imagem de 256 gray scale foi tratada como arquivo PCX no programa de PHOTIMPACT no WINDOWS. Foram escolhidas 74 imagens para $3 \mathrm{~m}, 66$ para $5 \mathrm{~m}$ e 67 para $7 \mathrm{~m}$ de largura de linha respectivamente.

\section{FERTILIDADE DO SOLO}

Análise química do solo foi feita em cada linha para verificar diferença de fertilidade e uma possível relação com desenvolvimento das espécies. A análises foi realizada 500 dias depois da abertura das linhas, sendo medidos o $\mathrm{pH}\left(\mathrm{H}_{2} \mathrm{O}\right)$ e os cinco macronutrientres: $\mathrm{N}, \mathrm{P}, \mathrm{K}, \mathrm{Ca}, \mathrm{Mg}$ e também, alumínio (Al), na camada $0-5 \mathrm{~cm}$ e $5-10 \mathrm{~cm}$. O número de amostras compostas foram 47 , sendo que para cada amostra, três sub amostras foram coletadas.

\section{CRESCIMENTO DAS PLÂNTULAS}

Os parâmetros biológicos avaliados em cada espécies foram; 1) Altura total (mm), 2) Diâmetro no colo (mm), 3) Índice de ganho foliar (número das folhas) e 4) concentração de clorofila foliar ( $a, b$ e total)

O crescimento foi avaliado pelas medições periódicas aos 54 , $85,165,235,305,337,369,393,441,471$ dias após a semeadura direta de S.micranthum, e para A. lecointei e C.goeldiana, aos 85, 156, 188, 220, 245, 292, 322 dias após o plantio. As mudas produzidas de A. lecointei e C.goeldiana mediram-se altura e diâmetro média de $9,56 \mathrm{~cm} / 16 \mathrm{~mm}$ e $6,53 \mathrm{~cm} /$
$18 \mathrm{~mm}$ respectivamente na hora de plantio. O conteúdo de clorofila foliar foi obtido pelo método tradicional de Arnon (1949) com a intensidade amostral de 10\% de todos indivíduos.

\section{RESULTADOS E DISCUSSÃO}

\section{AMBIENTE LUMÍNICO}

No processo de abertura das linhas, tentou-se delimitar a largura pelo estrato inferior da floresta. Porém, os limites não foram tão perfeitos como em uma linha reta. Devido a esta irregularidade nas larguras das linhas houve necessidade de uma caracterização pontual do ambiente lumínico em toda extensão das linhas. Os resultados obtidos pelos cálculos das fotos hemisféricas mostraram diferenças entre os ambientes lumínicos nas linhas em relação: $3 \mathrm{~m}<5 \mathrm{~m}=7 \mathrm{~m}$ para todos os parâmetros analisados (Tab.1). Já a radiação RFA instantânea (total) média medida pelo sensor em todos os pontos diferiu da média encontrada na linha de $7 \mathrm{~m}$.

Tabela 1 - Caracterização do ambiente lumínico nas três linhas de enriquecimento calculado através de fotografias hemisféricas. RFA: Radiação Fotossinteticamente Ativa. A unidade do valor é $\mathrm{mol}^{-m^{-2}} \cdot \mathrm{dia}^{-1}$. FDS: Fator direto de sítio, FIS: Fator indireto de sítio. A unidade do valor FDS/FIS são fração. * As letras diferentes expressam as diferenças pelo teste Tukey em $95 \%$ de probabilidade. $\mathrm{n}$ : número de observação.

\begin{tabular}{|c|c|c|c|c|c|c|}
\hline $\begin{array}{l}\text { Largura } \\
\text { da Linha }\end{array}$ & & $3 \mathrm{~m}$ & & $5 \mathrm{~m}$ & & $7 \mathrm{~m}$ \\
\hline & $n=74$ & $\begin{array}{l}\text { Erro Padrão } \\
\text { da média }\end{array}$ & $n=66$ & $\begin{array}{l}\text { Erro Padrão } \\
\text { da média }\end{array}$ & $n=67$ & $\begin{array}{l}\text { Erro Padrão } \\
\text { da média }\end{array}$ \\
\hline RFA Direto & $9.426 \mathrm{~b}$ & $\mp 0.613$ & $13.517 \mathrm{a}$ & $a \mp 0.499$ & $14.200 \mathrm{a}$ & 0.508 \\
\hline RFA Difusa & $1.279 \mathrm{~b}$ & $\mp 0.045$ & $1.637 \mathrm{a}$ & $\mp 0.044$ & $1.696 \mathrm{a}$ & 0.039 \\
\hline $\begin{array}{l}\text { Abertura de } \\
\text { Dossel (\%) }\end{array}$ & $16.009 b$ & $\mp 0.532$ & $19.770 \mathrm{a}$ & $a \mp 0.564$ & $20.780 \mathrm{a}$ & 0.489 \\
\hline FDS & $0.251 \mathrm{~b}$ & $\mp 0.016$ & $0.351 \mathrm{a}$ & $\mp 0.013$ & $0.367 \mathrm{a}$ & 0.013 \\
\hline FIS & $0.229 \mathrm{~b}$ & $\mp 0.008$ & $0.285 \mathrm{a}$ & ${ }_{\mp} \mathbf{0 . 0 0 8}$ & $0.293 \mathrm{a}$ & 0.007 \\
\hline $\begin{array}{l}\text { RFA Instantâneo } \\
\left(\mu \mathrm{mol} \cdot \mathrm{m}^{-2} \cdot \mathrm{s}^{-1}\right)\end{array}$ & $\begin{array}{l}332.74 a \\
(n=101)\end{array}$ & $\mp 51.89$ & $\begin{array}{l}323.99 a \\
(n=91)\end{array}$ & & $\begin{array}{l}286.64 b \\
(n=99)\end{array}$ & 41.76 \\
\hline
\end{tabular}

Em todas as linhas os valores encontrados são consideravelmente maiores do que os valores encontrados em estudos sobre avaliação de microclima da floresta tropical (Bazzaz \& Pickett, 1980; Bongers \& Popma, 1990; Hartshorn, 1990; Brown \& Whitmore, 1992; Brown, 1993; van Dam, 2001). Principalmente o ambiente lumínico entre $5 \mathrm{~m}$ e $7 \mathrm{~m}$ de largura, equivalente ao valor de porcentagem média da abertura de 19,7720,78\% corresponde a 4.020-5.100 $\mathrm{m}^{2}$ de abertura de dossel (Segundo programa Winphot). Do ponto de vista silvicultural, a decisão de se escolher uma determinada largura de linha para maior capacidade de captação de radiação baseia-se, sobretudo no custo operacional. Neste estudo as linhas de 5 e 7 metros apresentaram as mesmas característica. Portanto, pode-se se considerar que a linha de 5 metros é a mais adequada pois relativamente menos impacto e custo, necessitando de uma menor remoção da biomassa. Sobre o valor RFA instantânea, as 
linhas de $7 \mathrm{~m}$ tiveram valores inferiores aos encontrados nas linhas mais estreitas, e o valor de EPM (erro padrão da média) aumentam inversamente ao tamanho da clareira $3 \mathrm{~m}>5 \mathrm{~m}>7 \mathrm{~m}$ (Tab.1). Quanto ao EPM, o resultado corresponde à conclusão do Brown (1993) na avaliação de microclima nas clareiras de diferentes tamanhos, o coeficiente de variação entre parâmetros (RFA diária, temperatura, umidade relativa do ar) é maior em clareiras menores, e conforme aumenta de tamanho da clareira esta variação diminui.

Tabela 2 - Distribuição de valor RFA $\left(\mu \mathrm{mol} \cdot \mathrm{m}^{-2} \cdot \mathrm{s}^{-1}\right)$ entre três linhas de enriquecimento. *0 número de pontos de observação onde intercepta inferior a $3 \%$ e superior a $60 \%$ de RFA total no baixo de dossel.

\begin{tabular}{llll}
\hline & $\mathbf{3 m}(\mathbf{n}=\mathbf{1 0 1})$ & $\mathbf{5 m}(\mathbf{n}=\mathbf{9 1})$ & $\mathbf{7 m}(\mathbf{n}=\mathbf{9 9})$ \\
\hline RFA máxima & 2116,00 & 2146,00 & 2100,00 \\
RFA mínima & 17,37 & 36,36 & 48,05 \\
No. de pontos RFA $>60 \% *$ & 8 & 5 & 4 \\
No. de pontos RFA $<3 \% *$ & 38 & 20 & 10 \\
\hline
\end{tabular}

Devido à geometria das clareiras, as de menores tamanhos sofrem um maior variação microclimática do que as maiores (Brown, 1993). Este fato explica que os valores medidos refletiram a capacidade máxima de entrada da radiação durante o horário compreendido entre as 11:00-13:00h por linha, e não representaram a capacidade de captação de radiação total diária nas linhas. A distribuição da radiação RFA em cada largura de linha para os pontos que interceptam menos de $3 \%$ e mais de $60 \%$ da RFA total mostra a mesma tendência de entrada de radiação nas linhas (Tab.2). Isto evidencia uma maior oscilação de entrada da radiação durante o horário com forte radiação direta que ocorrem na linha de menor largura.

\section{A ANÁLISE QUÍMICA DO SOLO}

A análise química do solo amostrado nas linhas apresentou baixo valor de $\mathrm{pH}\left(\mathrm{H}_{2} \mathrm{O}\right)$ e alto teor de Al. Como a coleta do solo foi feita aproximadamente 500 dias após a abertura das linhas, provavelmente estes valores foram influenciados pela abertura das copas, como lixiviação, escoamento e insolação nas linhas (Tab.3).

Somente os valores de $\mathrm{pH}\left(\mathrm{H}_{2} \mathrm{O}\right)$ na camada de cinco a dez centímetros mostraram uma relação negativa com a ampliação das linhas pelo teste de Scheffé. Esta mudança pode ser um reflexo da alta heterogeneidade dos sítios. Observa-se uma diferença significativa no valor de Ca com a ampliação da linha, em ambas as camadas, e redução dos valores de $\mathrm{K}$ em camada de $5-10 \mathrm{~cm}$. Isto deve ser um resultado do intemperismo e lixiviação dos nutrientes devido à chuva e forte insolação encontrada nas clareiras grandes (Tabela 1).

Quando se compara soma de base, houve seguintes relaçōes entre linhas: $0,38 \mathrm{cmol} / \mathrm{dm}^{3}(3 \mathrm{~m})>0,35(5 \mathrm{~m})>0,29(7 \mathrm{~m}) \mathrm{em}$ profundidade de $0-5 \mathrm{~cm}$, e $0,19(3 \mathrm{~m})>0,17(5 \mathrm{~m})=0,17(7 \mathrm{~m})$ em profundidade de $5-10 \mathrm{~cm}$. Estes valores foram baixos, já o alumínio disponível apresentou uma alta concentração. Portanto, o solo provavelmente é distrófico, com toxidez por $\mathrm{Al}$ e evidentemente pode ser classificado como muito pobre (Tomé, 1997). Comparando os resultado encontrados neste estudo com a classificação de solo da América Tropical (Cochrane et al., 1984), pode-se dizer que todos os valores de $\mathrm{pH}$ são considerados baixo (< 5,3: baixo), assim também como os teores de $\mathrm{Ca}, \mathrm{Mg}, \mathrm{K}$. Todos os valores encontrados estão abaixo do padrão encontrado nesta região, exceto o teor de $\mathrm{Al}$ que é bastante alto (> 1,5 $\mathrm{cmol} \cdot \mathrm{dm}^{-3}$ : alto). Estes resultados representam uma elevada fitotoxidade para as mudas (Cochrane et al., 1984). De um modo geral, os resultado apresentaram uma condição bem pobre em nutrientes disponíveis e diferenças mínimas entre as três larguras de linhas.

\section{O ESTABELECIMENTO NAS LINHAS DE ENRIQUECIMENTO}

É prática em silvicultura tropical a recomendação de abertura de linhas de enriquecimento no sentido Leste-Oeste para otimizar

Tabela 3 - Caracterização do pH e a concentração dos nutrientes em diferentes profundidades do solo e por três linhas de enriquecimento. Novo AripuanãAM. Letra expressa diferença pelo teste de Duncan $(a=0,05) .{ }^{\star \star}$ expressa diferença pelo teste de Scheffé $(a=0,05)$. EP: Erro Padrão.

\begin{tabular}{|c|c|c|c|c|c|c|c|}
\hline & Profundidade $(\mathrm{cm})$ & $3 m$ & EP & $5 \mathrm{~m}$ & $\mathrm{EP}$ & $7 \mathrm{~m}$ & $\mathrm{EP}$ \\
\hline $\mathrm{pH}$ & $0-5$ & $3,5 \mathrm{ab}$ & 0,029 & $3,56 \mathrm{a}$ & 0,020 & $3,48 b$ & 0,028 \\
\hline$\left(\mathrm{H}_{2} \mathrm{O}\right)$ & $5-10$ & $3,66 b^{\star \star}$ & 0,027 & $3,72 a b$ & 0,961 & $3,76 a^{\star \star}$ & 0,941 \\
\hline $\mathrm{cmol}_{\mathrm{c}} \cdot \mathrm{dm}^{-3}$ & $5-10$ & $2,2 \mathrm{a}$ & 0,796 & $2,133 \mathrm{a}$ & 0,552 & $2 \mathrm{a}$ & 0,5 \\
\hline K & $0-5$ & $36,8 \mathrm{a}$ & 2,724 & $32,9 \mathrm{a}$ & 1,030 & $31,5 \mathrm{a}$ & 1,396 \\
\hline $\mathrm{mg} \cdot \mathrm{dm}^{-3}$ & $5-10$ & $22 \mathrm{a}$ & 2,199 & $18,2 a b$ & 4,716 & $17 \mathrm{~b}$ & 4,25 \\
\hline $\mathrm{Ca}$ & $0-5$ & $0,149 \mathrm{a}$ & 0,023 & $0,12 a b$ & 0,016 & $0,099 \mathrm{~b}$ & 0,007 \\
\hline $\mathrm{cmol}_{\mathrm{c}} \cdot \mathrm{dm}^{-3}$ & $5-10$ & $0,059 \mathrm{a}$ & 0,007 & $0,053 \mathrm{ab}$ & 0,014 & $0,045 \mathrm{~b}$ & 0,011 \\
\hline $\mathrm{Mg}$ & $0-5$ & $0,137 \mathrm{ab}$ & 0,013 & $0,147 \mathrm{a}$ & 0,018 & $0,108 \mathrm{~b}$ & 0,006 \\
\hline $\mathrm{cmol}_{\mathrm{c}} \cdot \mathrm{dm}^{-3}$ & $5-10$ & $0,075 \mathrm{a}$ & 0,007 & $0,067 \mathrm{a}$ & 0,017 & $0,084 \mathrm{a}$ & 0,021 \\
\hline $\mathrm{Al}$ & $0-5$ & 2,859 a & 0,095 & $2,832 \mathrm{a}$ & 0,087 & $2,827 \mathrm{a}$ & 0,090 \\
\hline $\mathrm{cmol}_{\mathrm{c}} \cdot \mathrm{dm}^{-3}$ & $5-10$ & $2,579 \mathrm{a}$ & 0,075 & $2,465 a b$ & 0,636 & $2,335 \mathrm{~b}$ & 0,584 \\
\hline g. $\mathrm{dm}^{-3}$ & $5-10$ & $1,753 \mathrm{a}$ & 0,249 & $1,855 \mathrm{a}$ & 0,757 & $1,319 \mathrm{a}$ & 0,439 \\
\hline
\end{tabular}


a captação de radiação solar. No entanto, para a fisiologia da planta o que importa é a quantidade de radiação direta e indireta incidente durante o total de horas no dia, mês e ano em seu ciclo de crescimento. Espécies que otimizam a RFA difusa (estabelecem e crescem em ambientes com alto valor de FIS) terão uma melhor performance do que em ambientes com alta RFA direta (baixo valor de FIS). Então, poder-se-ia supor que uma abertura nortesul (não recomendado nos manuais de silvicultura tropical) reduziria a incidência da RFA direta, mas manteria níveis aceitáveis de radiação indireta. Em uma simulação preliminar utilizando o programa WINPHOT (figura 1), houve uma resposta diferenciada conforme as larguras das linhas. Nas linhas de $3 \mathrm{~m}$ (norte-sul0, a simulaçãao mostrou haver uma redução de cerca de $10 \%$ da RFA direta e FDS e nas linhas de 5 e $7 \mathrm{~m}$ houve redução de $15 \%$ das mesmas, já a RFA difusa e FIS alteraram muito pouco, cerca de $0,5 \%$.
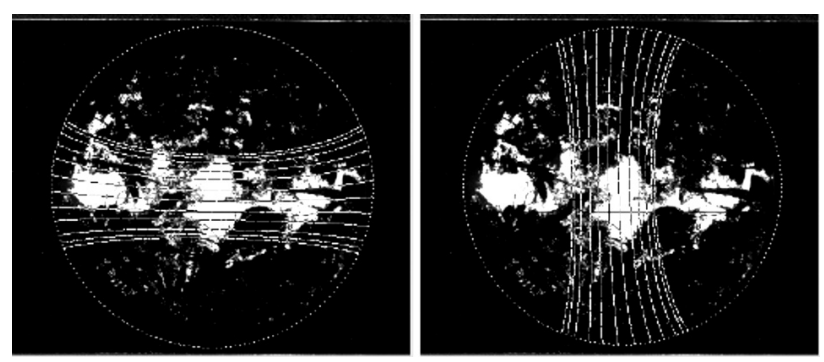

Figura 1 - A fotografia hemisférica com o uso de programa WINPHOT para a simulação de trajetória solar com a abertura da linha de enriquecimento. A esquerda é direção real da linha, leste-oeste, a direita é o caso de que a linha está em direção de norte-sul. A localidade é $5^{\circ} 18^{\prime} \mathrm{S}$ e $60^{\circ} 04^{\prime} \mathrm{W}$, município de Novo Aripuanã-Amazonas-Brasil.
Os mecanismos e funções das diferentes radiaçōes (difusa e direta) no crescimento e morfologia das plantas ainda carecem de estudos mais conclusivos (Ackerly \& Bazzaz, 1995). Como, a quantidade de radiação direta e indireta está sendo afetada pela largura e direção das linhas de enriquecimento, sugerem-se estudos de longo prazo testando estes efeitos da geometria e posição nas respostas fisiológicas em plântulas e arvoretas em florestas da Amazônia.

\section{DINÂMICA DO CRESCIMENTO DE PLÂNTULAS}

\section{Astronium lecointei Ducke}

Quanto ao crescimento, a espécie mostrou diferenças na altura entre linhas durante todo o período de observação, relacionando positivamente com a largura da linha: $3 \mathrm{~m}<5 \mathrm{~m}=7 \mathrm{~m}$ (Fig.2). $\mathrm{O}$ diâmetro mostrou a mesma relação na estação chuvosa. Esta espécie apresentou crescimento constante, principalmente de altura, competindo com outras espécies nativas em fase de regeneração. Esta tendência foi observada mesmo no período atípico de precipitação, sendo capaz de otimizar a captação em ambiente de alta radiação e uma possivelmente estratégia de resistência ao déficit hídrico das pequenas plântulas no centro das linhas. $\mathrm{O}$ índice de ganho foliar não mostrou diferenças entre as linhas. $\mathrm{O}$ índice evidenciou uma tendência relacionada negativamente com radiação RFA direta na estação seca prolongada (Fig.2).

Já pelas análises químicas do solo, os macro-nutrientes não influenciaram significativamente o crescimento conforme se modifica as larguras das linhas. O crescimento desta espécie relacionou-se positivamente com a quantidade de radiação direta e difusa. Esta relação foi mais nítida principalmente na estação chuvosa.
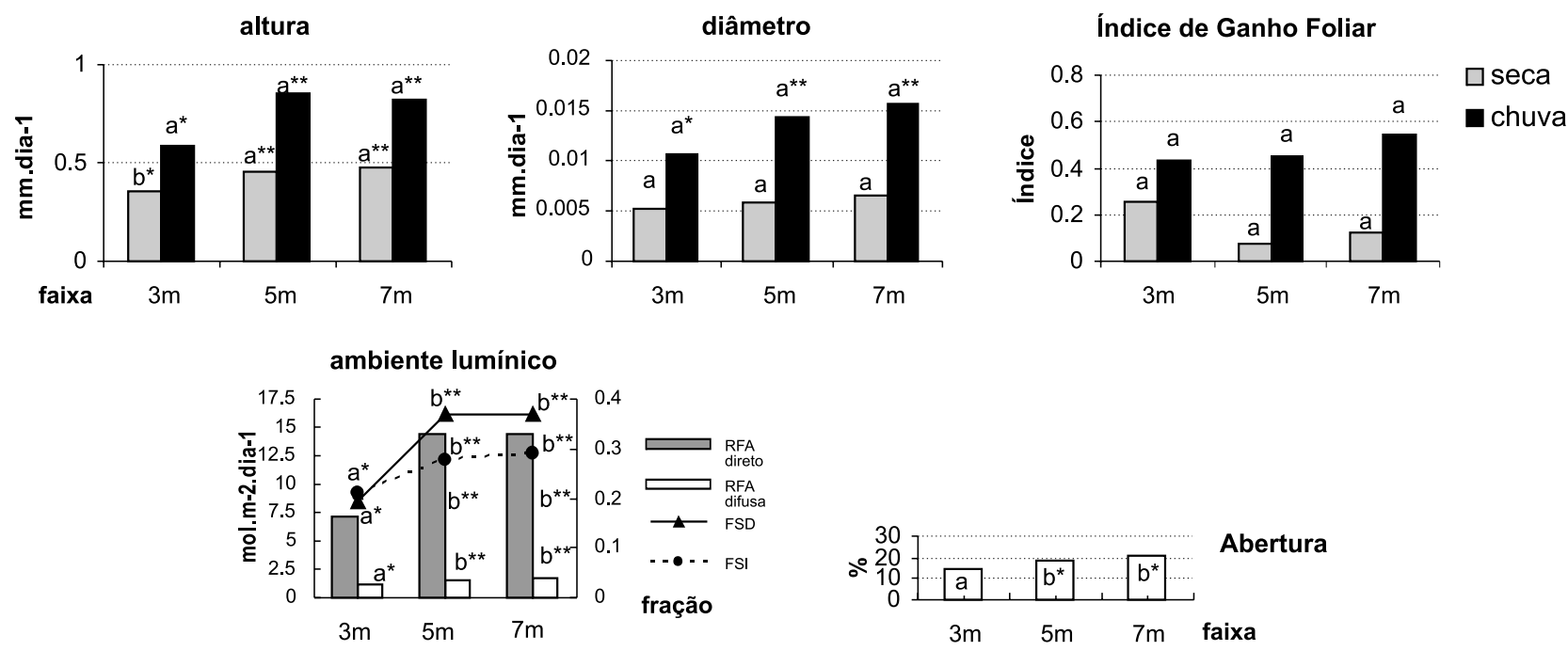

Figura 2 - Crescimento e comportamento de Astronium lecointei Ducke por estação seca / chuvosa, e seu ambiente lumínico. A letra indica diferença pelo teste de Duncan, $e^{* / *}$ indica diferença pelo teste de Tukey ao nível de $95 \%$ de probabilidade. 


\section{Scleronema micranthum Ducke}

O resultado do ambiente lumínico evidenciou a complexidade da forma de abertura das copas nas linhas (Fig.3).

Comparando o crescimento em altura dentro de cada estação não houve diferenças significativas entre as linhas. A espécie mostrou uma característica, onde entra mais RFA direta, aumenta a taxa de crescimento diamétrico na estação chuvosa. Isto pode significar que a espécie começa a crescer na condição otimizada pela combinação de recursos primários. Durante todo período de observação, o índice de ganho foliar é maior nas linhas de $3 \mathrm{~m}$ e $5 \mathrm{~m}$, relacionando-se negativamente com RFA difusa na estação seca.

\section{Cordia goeldiana Huber}

Dentro da comparação entre as linhas, o único parâmetro que apresentou diferenças significativas foi o diâmetro (Fig.4).

A altura e diâmetro mostraram correspondência positiva com a ampliação da linha, diferindo entre $3 \mathrm{~m}$ e 5-7m (Fig.4). O índice de ganho foliar não mostrou diferença entre as linhas. Mas quando se compara a aclimataçáo entre estação seca e chuvosa, mostrou-se claramente uma adaptação estratégica como abscisão e perda das folhas. O índice de ganho foliar da estação seca para a chuvosa apresentou uma diferença em mais de 14 vezes (chuva: $0,6186$ > seca: $0,0436 / p=0,0001)$, mostrando que a espécie é semidecídua (Montagner $\&$ Yared, 1982).
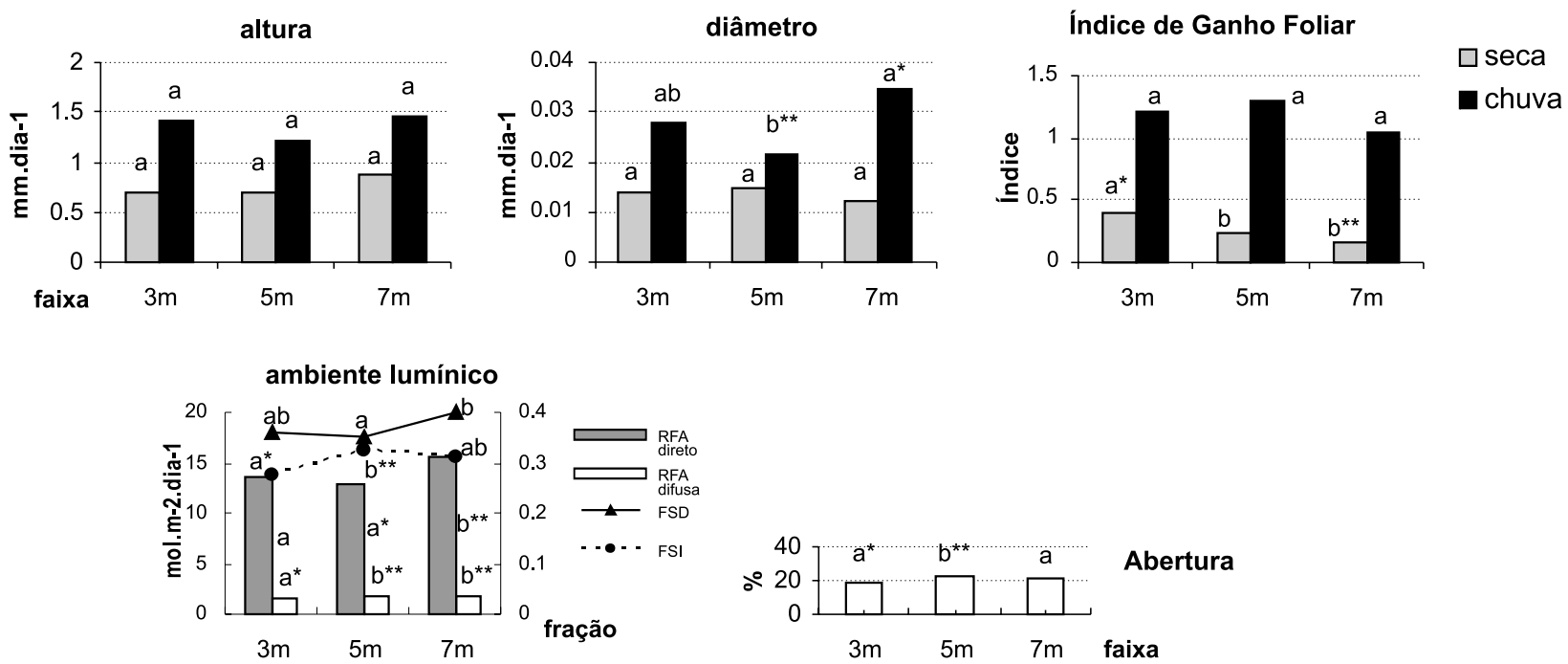

Figura 3 - Crescimento e comportamento de Scleronema micranthum Ducke por estação seca / chuvosa, e seu ambiente lumínico. A letra indica diferença pelo teste de Duncan, $e^{*} / * *$ indica diferença pelo teste de Tukey ao nível de $95 \%$ de probabilidade.
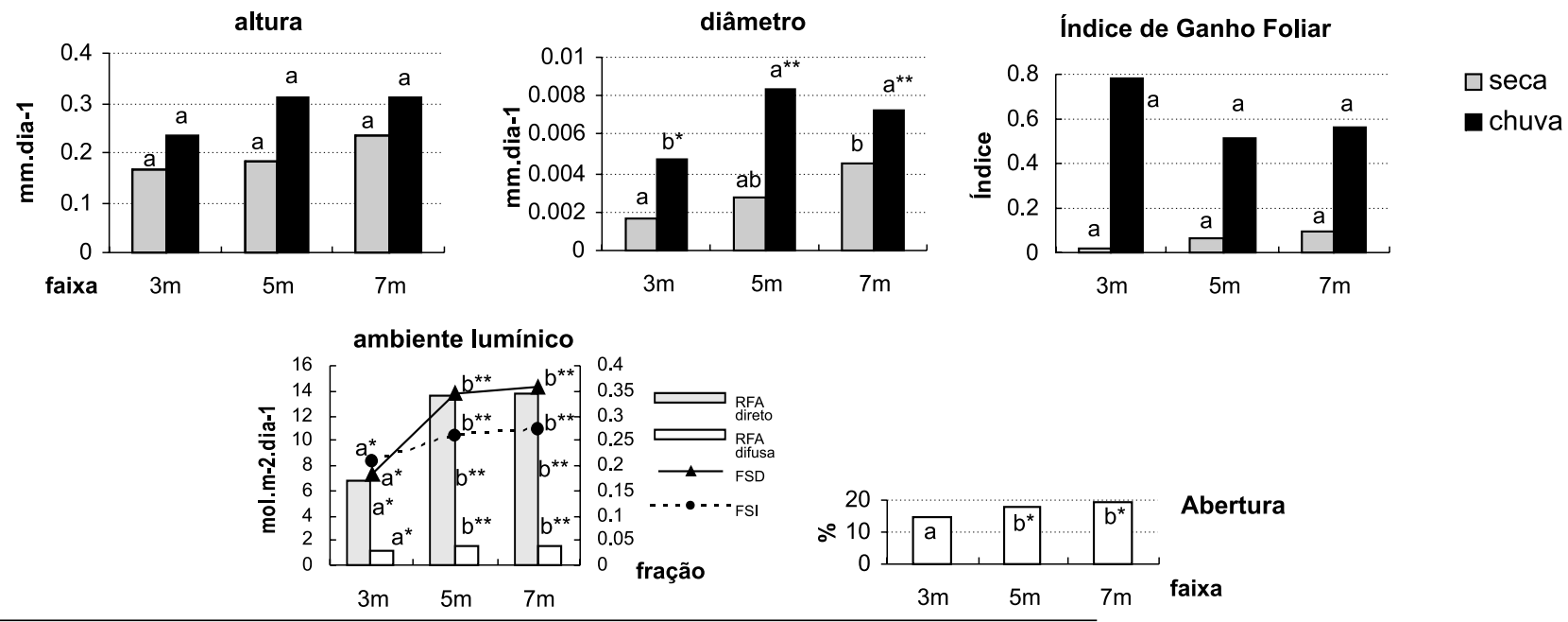

Figura 4 - Crescimento e comportamento de Cordia goeldiana Huber por estação Seca / chuvosa, e seu ambiente lumínico. A letra indica diferença pelo teste de Duncan, $e^{* / * *}$ indica diferença pelo teste de Tukey ao nível de $95 \%$ de probabilidade. 
Dentro da mesma largura de faixa, foram observados poucos indivíduos que cresceram de forma destacada, evidenciando alta sensibilidade no seu crescimento, às vezes mostrando maior vigor do que as outras regenerações naturais autóctones. Porém, esta variação é ínfima e não aparece na média calculada por faixa dentro do teste. Neste experimento não foram estudados em ambiente de dossel fechado, nem em pequenas clareiras. Isto poderia não mostrar toda característica de aclimatação desta espécie. Porém uma vez que é observada a presença de indivíduos de distinto crescimento, esta espécie pode possuir característica de rápida aclimatação de acordo com o ambiente. Bongers \& Popma (1988) observaram no seu experimento de Cordia megalantha Blake, uma característica de ligeira aclimatação, o que não ocorre em outras espécies testadas. Testando o crescimento em floresta contínua, clareira pequena e grande, observaram um melhor crescimento em pequenas clareiras, concluindo que a espécie é apta para microclimas encontrados em pequenas clareiras. Ao contrário, existem trabalhos com C.goeldiana que observaram um melhor crescimento com uma correlação positiva com a radiação solar. Comparando com o estudo de plantios com C.goeldiana no Pará, Yared (1985) documentou uma taxa de crescimento das plântulas muito maior do que neste experimento, principalmente na fase inicial, onde o plantio foi feito em forma de mudas em sistemas agroflorestais.

Apesar de que a relação com fatores lumínicos foi baixa, podese notar que existe uma diferença enre estação seca e chuvosa (Tab.4). Exceto os valores de altura da S.micranthum diante dos valores de RFA difusa e FIS, os parâmetros de crescimento indicaram uma tendência do aumento proporcional de relação com a radiação RFA direta, difusa, FDS e FIS entre diferentes estaçôes (Tab.4). Pelo teste, a única espécie que mostrou relação signifiactiva de seu crescimento com a radiação foi C.goeldiana durante todo período. Pode-se observar que esta tendência elevouse na estação chuvosa.

Scleronema micranthum na estação seca, apresentou coeficiente angular da reta negativo em altura com radiação RFA direta $\left(R^{2}\right.$ $=-0,011 / P=0,634)$, difusa $\left(R^{2}=-0,073 / P=0,203\right)$, FIS $\left(R^{2}\right.$ $=-0,084 / P=0,171)$ e FDS $\left(R^{2}=-0,012 / P=0,617\right)$, apesar de que coeficiente de regressão foi baixo (Tab.4) demonstrando tendência de fotoinibução. Porém, na estação chuvosa pode-se
Tabela 4 - Resultado de regressão simples entre plântulas e ambiente para três espécies. A"1"significa 0 valor de estação seca, "2" para estação chuvosa. * expressa diferença ao nível de 95\%. "Abertura": abertura de dossel em \%. 0 valor de entre parêntesis é probabilidade $P$.

\begin{tabular}{|c|c|c|c|c|c|c|}
\hline & \multicolumn{6}{|c|}{$\mathbf{R}^{2}$} \\
\hline & Abertura & RFA direto & RFA difusa & FSD & FSI & PAR instantânea \\
\hline \multicolumn{7}{|c|}{ Astronium lecointei Ducke } \\
\hline altura $1 \mathrm{~A}$ & $\begin{array}{l}0,025 \\
(0,316)\end{array}$ & $\begin{array}{l}0,001 \\
(0,834)\end{array}$ & $\begin{array}{l}0,031 \\
(0,258)\end{array}$ & $\begin{array}{l}-0,002 \\
(0,783)\end{array}$ & $\begin{array}{l}0,027 \\
(0,290)\end{array}$ & $\begin{array}{c}0,208 \\
(<0,001)^{*}\end{array}$ \\
\hline altura 2 & $\begin{array}{l}0,014 \\
(0,458)\end{array}$ & $\begin{array}{l}0,045 \\
(0,176)\end{array}$ & $\begin{array}{l}0,048 \\
(0,166)\end{array}$ & $\begin{array}{l}0,044 \\
(0,184)\end{array}$ & $\begin{array}{l}0,032 \\
(0,254)\end{array}$ & $\begin{array}{c}0,000 \\
(0,817)\end{array}$ \\
\hline diâmetro 1 & $\begin{array}{l}0,047 \\
(0,165)\end{array}$ & $\begin{array}{l}0,001 \\
(0,849)\end{array}$ & $\begin{array}{l}0,043 \\
(0,182)\end{array}$ & $\begin{array}{l}0,001 \\
(0,876)\end{array}$ & $\begin{array}{l}0,042 \\
(0,185)\end{array}$ & $\begin{array}{c}0,206 \\
(0,402)\end{array}$ \\
\hline diâmetro 2 & $\begin{array}{l}0,003 \\
(0,724)\end{array}$ & $\begin{array}{l}0,006 \\
(0,631)\end{array}$ & $\begin{array}{l}0,016 \\
(0,429)\end{array}$ & $\begin{array}{l}0,004 \\
(0,683)\end{array}$ & $\begin{array}{l}0,001 \\
(0,536)\end{array}$ & $\begin{array}{c}0,200 \\
(0,003)^{*}\end{array}$ \\
\hline \multicolumn{7}{|c|}{ Cordia goeldiana Huber } \\
\hline altura 1 & $\begin{array}{l}0,112 \\
(0,087)\end{array}$ & $\begin{array}{l}0,199 \\
(0,020)^{*}\end{array}$ & $\begin{array}{l}0,172 \\
(0,031)^{*}\end{array}$ & $\begin{array}{l}0,225 \\
(0,013)^{*}\end{array}$ & $\begin{array}{l}0,180 \\
(0,027)^{*}\end{array}$ & $\begin{array}{c}0,067 \\
(0,194)\end{array}$ \\
\hline altura 2 & $\begin{array}{l}0,193 \\
(0,025)^{*}\end{array}$ & $\begin{array}{l}0,290 \\
(0,005)^{*}\end{array}$ & $\begin{array}{l}0,217 \\
(0,016)^{*}\end{array}$ & $\begin{array}{l}0,321 \\
(0,003)^{*}\end{array}$ & $\begin{array}{l}0,235 \\
(0,012)^{*}\end{array}$ & $\begin{array}{c}0,017 \\
(0,528)\end{array}$ \\
\hline diâmetro 1 & $\begin{array}{l}0,104 \\
(0,101)\end{array}$ & $\begin{array}{l}0,224 \\
(0,013)^{*}\end{array}$ & $\begin{array}{l}0,172 \\
(0,031)^{*}\end{array}$ & $\begin{array}{l}0,220 \\
(0,014)^{*}\end{array}$ & $\begin{array}{l}0,163 \\
(0,037)^{\star}\end{array}$ & $\begin{array}{c}0,099 \\
(0,111)\end{array}$ \\
\hline diâmetro 2 & $\begin{array}{l}0,159 \\
(0,044)^{*}\end{array}$ & $\begin{array}{l}0,290 \\
(0,005)^{\star}\end{array}$ & $\begin{array}{l}0,262 \\
(0,008)^{*}\end{array}$ & $\begin{array}{l}0,299 \\
(0,004)^{*}\end{array}$ & $\begin{array}{l}0,247 \\
(0,010)^{*}\end{array}$ & $\begin{array}{c}0,006 \\
(0,697)\end{array}$ \\
\hline \multicolumn{7}{|c|}{ Scleronema micranthum Ducke } \\
\hline altura 1 & $\begin{array}{l}-0,123 \\
(0,093)\end{array}$ & $\begin{array}{l}-0,011 \\
(0,634)\end{array}$ & $\begin{array}{l}-0,073 \\
(0,203)\end{array}$ & $\begin{array}{l}-0,012 \\
(0,617)\end{array}$ & $\begin{array}{l}-0,084 \\
(0,171)\end{array}$ & $\begin{array}{c}0,035 \\
(0,344)\end{array}$ \\
\hline altura 2 & $\begin{array}{l}-0,132 \\
(0,081)\end{array}$ & $\begin{array}{l}0,075 \\
(0,194)\end{array}$ & $\begin{array}{l}-0,012 \\
(0,611)\end{array}$ & $\begin{array}{l}0,076 \\
(0,193)\end{array}$ & $\begin{array}{l}-0,010 \\
(0,641)\end{array}$ & $\begin{array}{c}0,020 \\
(0,471)\end{array}$ \\
\hline diâmetro 1 & $\begin{array}{l}0,001 \\
(0,890)\end{array}$ & $\begin{array}{l}0,049 \\
(0,292)\end{array}$ & $\begin{array}{l}0,015 \\
(0,564)\end{array}$ & $\begin{array}{l}-0,035 \\
(0,383)\end{array}$ & $\begin{array}{l}0,038 \\
(0,362)\end{array}$ & $\begin{array}{c}0,017 \\
(0,513)\end{array}$ \\
\hline diâmetro 2 & $\begin{array}{l}0,037 \\
(0,367) \\
\end{array}$ & $\begin{array}{l}0,073 \\
(0,201) \\
\end{array}$ & $\begin{array}{l}0,001 \\
(0,905) \\
\end{array}$ & $\begin{array}{l}0,079 \\
(0,184) \\
\end{array}$ & $\begin{array}{l}0,007 \\
(0,703) \\
\end{array}$ & $\begin{array}{c}0,024 \\
(0,429) \\
\end{array}$ \\
\hline
\end{tabular}

observar uma tendência de utilização da radiação direta $\left(R^{2}=\right.$ $0,075 / P=0,194)$ e da FDS $\left(R^{2}=0,076 / P=0,193\right)$ no crescimento em altura (Tab.4).

\section{TEOR DE CLOROFILA FOLIAR}

O resultado da determinação do teor de clorofila reflete a tendência e a peculiaridade da plasticidade fisiológica das espécies sob a condiçẫo de clareiras grandes, onde as condiçōes ambientais podem ser severas para as plântulas jovens.

Entre as três espécies estudadas, a quantidade de clorofila $a$ é maior do que a clorofila $b$ em todos ambientes (Fig.5). Isto correspondeu com os trabalhos anteriores de espécies tolerantes à
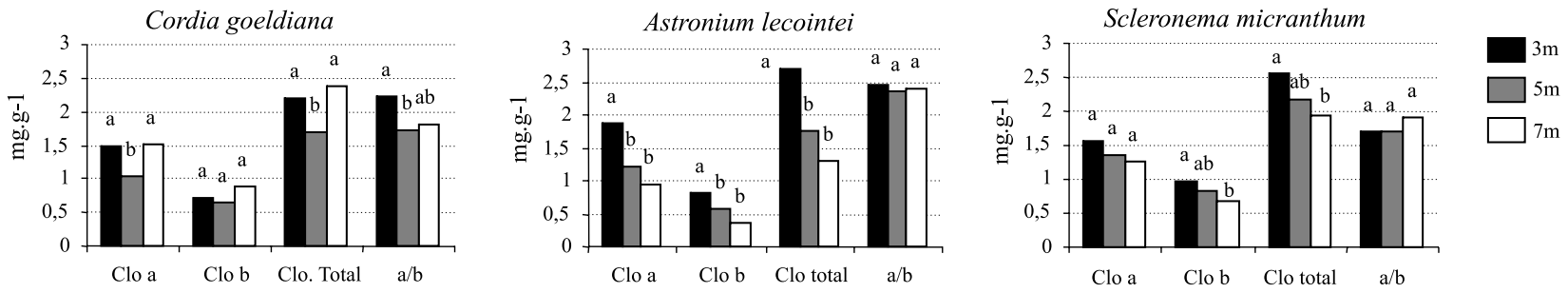

Figura 5 - A comparação de teor de clorofila de três espécies por linha de enriquecimento. A letra indica diferença pelo teste de Duncan ao nível de $95 \%$ de probabilidade. $3 \mathrm{~m} / 5 \mathrm{~m} / 7 \mathrm{~m}$ : largura de linha de plantio. 
Tabela 5 - Regressão simples de clorofila e ambiente de três espécies. * expressa significância ao nível de 95\%. "Abertura": abertura de dossel em $\%$. 0 valor de entre parêntesis é probabilidade $P$.

\begin{tabular}{|c|c|c|c|c|c|c|}
\hline & \multicolumn{6}{|c|}{$\mathbf{R}^{2}$} \\
\hline & Abertura & RFA direto & RFA difusa & FSD & $\mathrm{FSI}$ & PAR instantânea \\
\hline \multicolumn{7}{|l|}{ A. lecointei } \\
\hline Clorofila a & $\begin{array}{l}-0,338 \\
(0,01)^{*}\end{array}$ & $\begin{array}{l}-0,299 \\
(0,02)^{*}\end{array}$ & $\begin{array}{l}-0,388 \\
(0,01)^{\star}\end{array}$ & $\begin{array}{l}-0,285 \\
(0,02)^{\star}\end{array}$ & $\begin{array}{l}-0,342 \\
(0,01)^{\star}\end{array}$ & $\begin{array}{l}0,008 \\
(0,73)\end{array}$ \\
\hline Clorofila b & $\begin{array}{l}-0,305 \\
(0,02)^{\star}\end{array}$ & $\begin{array}{l}-0,206 \\
(0,06)\end{array}$ & $\begin{array}{l}-0,219 \\
(0,03)^{*}\end{array}$ & $\begin{array}{l}-0,211 \\
(0,06)\end{array}$ & $\begin{array}{l}-0,259 \\
(0,03)^{\star}\end{array}$ & $\begin{array}{l}0,016 \\
(0,62)\end{array}$ \\
\hline Clorofila total & $\begin{array}{l}-0,346 \\
(0,01)^{\star}\end{array}$ & $\begin{array}{l}-0,282 \\
(0,02)^{\star}\end{array}$ & $\begin{array}{l}-0,366 \\
(0,01)^{\star}\end{array}$ & $\begin{array}{l}-0,274 \\
(0,03)^{\star}\end{array}$ & $\begin{array}{l}-0,331 \\
(0,01)^{*}\end{array}$ & $\begin{array}{l}0,011 \\
(0,68)\end{array}$ \\
\hline Razão a/b & $\begin{array}{l}-0,332 \\
(0,02)^{\star}\end{array}$ & $\begin{array}{l}-0,276 \\
(0,04)^{\star}\end{array}$ & $\begin{array}{l}-0,399 \\
(0,01)^{\star}\end{array}$ & $\begin{array}{l}-0,267 \\
(0,04)^{\star}\end{array}$ & $\begin{array}{l}-0,359 \\
(0,01)^{\star}\end{array}$ & $\begin{array}{l}0,007 \\
(0,75)\end{array}$ \\
\hline \multicolumn{7}{|c|}{ S. micranthum } \\
\hline Clorofila a & $\begin{array}{l}-0,067 \\
(0,25)\end{array}$ & $\begin{array}{l}-0,041 \\
(0,37)\end{array}$ & $\begin{array}{l}-0,145 \\
(0,08)\end{array}$ & $\begin{array}{l}-0,048 \\
(0,33)\end{array}$ & $\begin{array}{l}-0,148 \\
(0,08)\end{array}$ & $\begin{array}{l}0,202 \\
(0,04)^{\star}\end{array}$ \\
\hline Clorofila b & $\begin{array}{l}-0,062 \\
(0,26)\end{array}$ & $\begin{array}{l}-0,061 \\
(0,27)\end{array}$ & $\begin{array}{l}-0,175 \\
(0,05)\end{array}$ & $\begin{array}{l}-0,054 \\
(0,30)\end{array}$ & $\begin{array}{l}-0,158 \\
(0,07)\end{array}$ & $\begin{array}{l}0,126 \\
(0,11)\end{array}$ \\
\hline Clorofila total & $\begin{array}{l}-0,073 \\
(0,22)\end{array}$ & $\begin{array}{l}-0,056 \\
(0,29)\end{array}$ & $\begin{array}{l}-0,180 \\
(0,05)^{\star}\end{array}$ & $\begin{array}{l}-0,051 \\
(0,28)\end{array}$ & $\begin{array}{l}-0,172 \\
(0,06)\end{array}$ & $\begin{array}{l}0,185 \\
(0,05)^{\star}\end{array}$ \\
\hline Razão a/b & $\begin{array}{l}0,007 \\
(0,75)\end{array}$ & $\begin{array}{l}0,003 \\
(0,84)\end{array}$ & $\begin{array}{l}-0,017 \\
(0,61)\end{array}$ & $\begin{array}{l}-0,014 \\
(0,66)\end{array}$ & $\begin{array}{l}-0,029 \\
(0,51)\end{array}$ & $\begin{array}{l}0,113 \\
(0,19)\end{array}$ \\
\hline \multicolumn{7}{|l|}{ C. goeldiana } \\
\hline Clorofila a & $\begin{array}{l}0,639 \\
(0,03)^{*}\end{array}$ & $\begin{array}{l}0,250 \\
(0,10)\end{array}$ & $\begin{array}{l}0,471 \\
(0,01)^{\star}\end{array}$ & $\begin{array}{l}0,183 \\
(0,17)\end{array}$ & $\begin{array}{l}0,419 \\
(0,02)^{*}\end{array}$ & $\begin{array}{l}0,164 \\
(0,03)^{\star}\end{array}$ \\
\hline Clorofila b & $\begin{array}{l}0,084 \\
(0,36)\end{array}$ & $\begin{array}{l}0,004 \\
(0,85)\end{array}$ & $\begin{array}{l}0,149 \\
(0,22)\end{array}$ & $\begin{array}{l}0,004 \\
(0,85)\end{array}$ & $\begin{array}{l}0,142 \\
(0,23)\end{array}$ & $\begin{array}{l}0,268 \\
(0,07)\end{array}$ \\
\hline Clorofila total & $\begin{array}{l}0,030 \\
(0,07)\end{array}$ & $\begin{array}{l}0,127 \\
(0,26)\end{array}$ & $\begin{array}{l}0,386 \\
(0,03)^{*}\end{array}$ & $\begin{array}{l}0,095 \\
(0,33)\end{array}$ & $\begin{array}{l}0,351 \\
(0,04)^{*}\end{array}$ & $\begin{array}{l}0,121 \\
(0,27)\end{array}$ \\
\hline Razão a/b & $\begin{array}{l}0,658 \\
(0,05) \\
\end{array}$ & $\begin{array}{l}0,773 \\
(0,02)^{*}\end{array}$ & $\begin{array}{l}0,880 \\
(0,01)^{*}\end{array}$ & $\begin{array}{l}0,860 \\
(0,01)^{*}\end{array}$ & $\begin{array}{l}0,915 \\
(0,66)^{*}\end{array}$ & $\begin{array}{l}0,598 \\
(0,07) \\
\end{array}$ \\
\hline
\end{tabular}

sombra (Cariniana micrantha) e espécie oportunista (Copaifera multijuga) desta região (Imakawa 1996; Elias 1997).

Astronium lecointei apresentou maior concentração de clorofila $a(\mathrm{~F}=9,08 / P=0,0009), b(\mathrm{~F}=8,89 / P=0,001)$ e total $(\mathrm{F}=$ $9,98 / P=0,0005)$ nas linhas de menor largura pelo teste de Duncan (Fig.5). A clorofila $a$ desta espécie mostrou uma relação contrária ao aumento da radiação conforme a regressão (Tab.5). O valor de clorofila $b(\mathrm{~F}=3,14 / P=0,06)$, e conseqüentemente a clorofila total $(\mathrm{F}=2,90 / P=0,074)$, de S.micranthum mostraram relativamente maior valor em menor largura da linha (Fig.5), e resultou relação inversa com a entrada de RFA difusa e FIS (Tab.5). O valor de C. goeldiana mostrou uma tendência irregular em relação à largura das linhas com maior teor de clorofila $a$ e $b$ em $7 \mathrm{~m}$ de linhas (Fig.5), sendo deduzido que a espécie não demonstrou uma afinidade de seu aparato fotossintético quanto às mudanças ambientais em seu estabelecimento.

Astronium lecointei mostrou mudança significativa de concentração de pigmentos entre os diferentes ambientes lumínicos testados, resultando que esta espécie possui relativamente alta plasticidade fisiológica entre os pigmentos fotossintéticos para otimizar seu estágio de estabelecimento.

$\mathrm{Na}$ linha de 3m, comparando o teor de clorofila $\boldsymbol{b}$, entre três espécies, $S$. micranthum apresentou maior concentração deste pigmento. Isto afirma a função de clorofila $b$, que é vantajosa em condição de sombra, já que este pigmento permite uma maior eficiência de absorção de luz menos intensa (Whatley $\&$ Whatley, 1982). Esta eficiência de aclimatação de clorofila $b$ infere que o habitat de S.micranthum seja local com menor radiação.

Dentro dos valores, há necessidade de levar em consideração quanto à possibilidade de influência do estresse por alta irradiação devido ao tamanho da clareira. Alta radiação pode causar em plantas um excesso de aquecimento de folhas, fotoxidação de pigmentos fotossintéticos e estresse hídrico (Brown, 1990; Vieira, 1996). Weis \& Berry (1988) sugeriram também que alta temperatura pode resultar na alteração de estrutura de pigmento utilizado pelo tilacoide na fotossíntese. Na ocorrência de alteração do sistema fotossintético, logicamente altera também a normalidade das funçôes e aparece em valores anormais.

Quanto à razão $\boldsymbol{a} / \boldsymbol{b}$ de clorofila, $S$. micranthum apresentou uma leve tendência de maior valor em linha de $5 \mathrm{~m}$, correspondendo a uma maior radiação RFA direta e difusa. Esta tendência deve ser ampliada em ambiente mais diferenciado coincidindo ao princípio que quanto maior a radiação, maior éo valor de razão $\boldsymbol{a} / \boldsymbol{b}$ (Hoflacher $\&$ Bauer, 1982).

$\mathrm{Na}$ análise de regressão, mesmo apresentando valores baixos dos coeficientes de regressão, pode-se caracterizar uma tendência de relação entre teor de clorofila das plântulas e ambientes. $\mathrm{O}$ teor de clorofila $a$ de $A$. lecointei mostrou uma tendência inversamente proporcional com a radiação RFA direta, difusa, FDS e FIS, e os teores de clorofila $b$ relacionou inversamente com radiação RFA difusa e FIS (Tab.5).

Os teores de clorofila $a$ de $A$. lecointei mostraram uma tendência inversamente proporcional com a radiação RFA, já a clorofila $b$ relacionou-se inversamente com a radiação RFA difusa e FIS. Em S. micranthum a concentração de clorofila $\boldsymbol{a}$ e $\boldsymbol{b}$ foi inversamente proporcional à radiação RFA difusa e FIS (Tab.5).

Os teores de Clorofila $a$ e total de C. goeldiana também apresentaram uma relação inversa com a radiaçāo RFA difusa. Já para a radiação direta esta relação é menos acentuada.

Aqui, pode-se confirmar a capacidade de aclimatação em $A$. lecointei somente observando o teor do pigmento fotossintético.

Astronium lecointei : Houve diferenças de crescimento em altura entre as larguras das linhas, como também na variação sazonal, o que resultou num constante crescimento. Esta mudança morfológica também deve estar associada às mudanças fisiológicas que foram nítidas nos teores de clorofila $a, b$ e total, inversamente proporcionais aos tamanhos das clareiras

Scleronema micranthum : Houve relação negativa do crescimento com a radiação RFA direta e FDS na estação seca, como também diferenciou-se pela largura da linha. Com o aumento da precipitação, inverteu-se a relação com a radiação e evidenciou a mudança do crescimento diamétrico e índice de ganho foliar. A observação da relação negativa da concentração 
de pigmentos, principalmente Clorofila $b$, com o aumento da radiação RFA difusa, confirma-se esta mudança fisiológica.

Cordia goeldiana: apresentou mudanças no crescimento em diâmetro durante o período de observação nas três larguras de linhas, existindo um aumento significativo do diâmetro e número de folhas com o aumento da umidade (precipitação). Conclui-se que estas mudanças morfológicas são conseqüências da plasticidade fisiológica, como foi observado no aparelho fotossintético, tais como no teor de clorofila.

Observando-se os resultados de crescimento em altura e diâmetro, do ponto de vista do fator luz para A. lecointei, podese supor que esta espécie é capazes de crescer em clareiras grandes, onde haja uma maior incidência da radiação direta e difusa. Enquanto isso $S$. micranthum poderia até crescer melhor em ponto de menor radiação, como clareiras pequenas. Em A. lecointei a aclimatação fisiológica foi mais evidente em condiçôes de clareira grande. Como espécies tolerantes à sombra aclimatam-se melhor fisiologicamente do que morfologicamente (Loach, 1970), enquanto que as espécies intolerante comportam-se de forma contrária (Kwesiga \& Grace,1986).

Comparando as espécies de ambos grupos ecológicos, sucessionais precoces (pioneiras) ou tolerantes à sombra (clímax), observa-se uma maior plasticidade morfológica em espécies pioneiras e uma menor em espécies tolerantes à sombra (Oberbauer \& Strain, 1984; 1986). Porém, existem certas espécies clímax que possuem uma alta plasticidade morfológica. Algumas espécies clímax exigem muito pouca radiação, ao contrário, com alta radiação imediatamente morrem. O primeiro tipo assemelhase muito com espécie pioneira (Swaine $\&$ Whitmore, 1988).

A. lecointei pode ter característica de tolerante à sombra ao mesmo tempo ela possui alta resistência para estiagem, e vigor com adição de outro recurso como umidade. Portanto, o fato conduz a conclusão de que a espécie possui larga amplitude de habitat entre as espécies testadas.

C. goeldiana provavelmente não apresenta boa aclimatação na região do experimento em termo de crescimento. Isto pode ocorrer devido às condiçóes edáficas, tais como: Latossolo Amarelo, Álico com baixo $\mathrm{pH}$ e o não uso de adubação. A mesma demonstrou relação significativa entre todos parâmetros de crescimento e todos tipos de radiação RFA, e apresentou também a plasticidade fisiológica contra radiação RFA difusa. Pode-se observar a aclimatação ao ambiente lumínico, embora seu crescimento seja baixo.

A C. goeldiana é uma das espécies mais estudadas silviculturalmente na Amazônia brasileira. O resultado de seu crescimento neste estudo foi bastante baixo comparado à de outros estudos na Amazônia. Como há falta de estudos sobre $A$. lecointei, é difícil fazer uma mesma analogia. Portanto, não se tem parâmetros suficientes para definição de crescimento neste sítio para esta espécie.

\section{CONGRUÊNCIA DE RECURSOS}

Para todas as espécies o melhor crescimento foi observado na estação chuvosa. Ocasião em que as espécies mostraram totalmente sua aclimatação à uma maior disponibilidade de um outro recurso (água da precipitação). O grau de aclimatação é um fator importante a se considerar nesta fase inicial do estabelecimento de plântulas.

Astronium lecointei e C. goeldiana na estação chuvosa mostraram maior crescimento em linhas onde ocorreram maiores incidências da radiação RFA (direta+difusa). Mas em $S$. micranthum registrou-se o maior crescimento diamétrico onde ocorreu menor radiação RFA direta e maior valor de FIS $(7 \mathrm{~m})$ na estação seca. Já na estação chuvosa esta espécie apresentou um maior crescimento na linha de maior radiação RFA direta.

Quanto ao índice de ganho foliar, C. goeldiana $\left(P_{\text {seca }}=0,920 /\right.$ $\left.P_{\text {chuva }}=0,387\right)$ e $A$. lecointei $\left(P_{\text {seca }}=0,426 / P_{\text {chuva }}=0,238\right)$ não mostraram diferenças significativas entre linhas, somente, aumentou-se o número de folhas da estação seca para a chuvosa. Já para S. micranthum houve um maior IGF na seca em áreas com menor abertura do dossel, acompanhado com menor FIS. Já na estação chuvosa aumentou o índice em maiores aberturas do dossel e de FIS. Avaliando seu comportamento morfológico e fisiológico, ela apresentou alta fragilidade à combinação dos fatores de radiação com a disponibilidade hídrica.

Considerando também o fato de que alterou moderadamente o teor de clorofila contra RFA difusa e FIS, portanto, esta espécie pode ser considerada intermediária. Para estas espécies o melhor crescimento foi observado na estaçăo chuvosa. Ocasião em que as espécies mostraram totalmente sua aclimatação à uma maior disponibilidade de um outro recurso (água da precipitação). $\mathrm{O}$ grau de aclimatação é um fator importante a se considerar nesta fase inicial do estabelecimento de plântulas.

A adição de nutrientes químicos em plântulas de $A$. lecointei poderia melhorar a sua performance (sobrevivência + desenvolvimento) na introdução em clareiras ou em linhas. Por exemplo, as folhas de alta produtividade requerem N, P e outros nutrientes minerais para criar reservatório de enzimas e pigmentos necessários para sustentar alta taxa de assimilação (Field \& Mooney, 1986). Otimizando as condiçóes edáficas poderia revelar as capacidades inerentes das espécies como $A$. lecointei que possui um nicho relativamente amplo.

Vários estudos tem sugerido uma classificação em grupo ecológicos em relação à vários fatores, tais como: umbrófila, modos de dispersão, tamanho de semente e modos de germinação, etc. (Boardman, 1977; Swaine \& Whitmore, 1988; Whitmore, 1990).

No entanto, outros autores sugerem que a história de vida das espécies é muito mais importante para definir o conceito de exigências lumínicas (Clark \& Clark, 1984), o conceito de grupo ecológico não deve ser compreendido somente com informações 
isoladas de um fator ambiental como luz. Como exemplo tem-se o resultado de $S$. micranthum. Houve um maior crescimento diamétrico em ambiente de menor radiação RFA direta e maior FIS na estação seca. Já com o aumento de umidade inversamente marcou o maior crescimento na linha de maior radiação RFA direta. Por este fato, pode-se notar que a espécie é sensível com a forte insolação, em termos de radiação RFA direta. Thompson et al. (1992) comparou a espécie exigente à luz, intermediária e tolerante à sombra nas diferentes condições combinadas de sombra e nutrientes (nitrogênio). $\mathrm{O}$ autor concluiu que as plântulas não crescem sob alta radiação sem suficiente nutriente entre todas espécies, tanto em espécie pioneiras como toleranteà sombra. Isto reforça a teoria da combinação de recursos sugerida por Tilman (1985). Quando caracterizar o estabelecimento das plântulas de uma espécie em relação ao seu grupo ecológico, deve-se avaliar o aspecto dinâmico na circunstância em que a espécie enfrenta durante seu desenvolvimento. Não devendo somente considerar uma fase pontual.

Em um estudo silvicultural, Yared (1985) testou vários sistemas e concluiu que o melhor crescimento da $C$. goeldiana foi encontrado em pleno sol e nos plantios agroflorestais, e menor em linhas de enriquecimento. Pela avaliação concluiu-se que o fator determinante foi a quantidade de radiação. Bongers $\&$ Popma (1988) sugeriram para Cordia megalantha seria uma especialista de pequenas clareiras. Isto enuncia a necessidade de estudo com mais fatores, do ponto de vista de congruência dos recursos. A espécie tolerante à sombra, ou intermediária não possui a mesma capacidade de ocupação das clareiras como tem as pioneiras. Porém, em condições favoráveis tais como um aumento ocasional da disponibilidade de nutrientes ou umidade do solo, as plantas podem crescer melhor quanto maior for a radiação nas clareiras, mesmo que não sejam as espécies pioneiras.

C. goeldiana mostrou maior coeficiente de variação do crescimento em altura entre as outras espécies estudadas $(C$. goeldiana: $113>$ A. lecointei: 60,6 > S. micranthum: 59,7). Este maior crescimento observado em $C$. goeldiana, deve-se ao fator de que nas linhas de 5 e $7 \mathrm{~m}$ foram observados um crescimento atípico e superior em alguns indivíduos. A espécie C. goeldiana, portanto, sendo considerada oportunista ou intermediário, dependendo da disponibilidade de recursos primários poderia ter seu habitat ampliado.

\section{FATOR LIMITANTE E ESTRESSE}

Embora as plântulas não tenham morrido de imediato, observou-se que a grande quantidade de radiação direta e difusa incidente, funcionou as vezes como um fator limitante para as plântulas. A alta radiação na estação seca que propiciou mudanças comportamentais nas espécies deve ter causado o excesso de transpiração e fotooxidação nas plântulas no diferente habitat. Em condições naturais de alta radiação solar a densidade de espécies tolerantes à sombra é muito baixa. Portanto, estas espécies são menos aptas a se adaptarem aos locais abertos tais como grandes clareiras (Oberbauer et al., 1993).

Segundo afirmação de HAMMOND (1995), a sobrevivência de plântulas na sucessão é mais influenciada por fatores fisiológicos como estresse hídrico devido à alta evaporação da superfície, do que com os ataque de patógenos e predação. As observaçôes de campo mostraram que as plântulas no final deste estudo provavelmente foram influenciadas pelo estresse hídrico, devido o ano atípico com a presença de El niño, não havendo evidência de ataque de patógenos, nem de predação.

Dentro dos valores medidos, há necessidade de levar em consideração quanto à possibilidade de influência de estresse por alta irradiação devido ao tamanho da clareira. Alta radiação pode causar em plantas um excesso de aquecimento de folhas, fotooxidação de pigmentos fotossintéticos e estresse hídrico (Brown, 1990; Vieira, 1996). Weis \& Berry (1988) sugeriram também que alta temperatura pode resultar na alteração de estrutura de pigmento utilizado na tilacoide em fotossíntese. $\mathrm{Na}$ ocorrência de alteração do sistema fotossintético, logicamente altera também a normalidade das funçōes e aparece em valores anormais.

\section{CONCLUSÃO}

As linhas de $5 \mathrm{~m}$ e $7 \mathrm{~m}$ possuem semelhaças na estrada das radiaçôes $P A R$ direta e difusa.

As linhas acima de $5 \mathrm{~m}$ pertencem a categoria de clareira grande (a proporção de abertura do dossel é 19,77-20,78\%, equivalente $\mathrm{a}>4.000 \mathrm{~m}^{2}$ de abertura).

Cordia goeldiana, mostrou-se exigente à radiaçāo direta e difusa com a disponibilidade de outro recurso primário, como suficiente disposição da água no solo. A espécie é considerada uma espécie heliófila, oportunista de clareira,

Astronium lecointei apresentou uma maior resistência durante o excesso de chuva e forte seca. A espécie sendo tolerante à sombra, mostrou também uma maior plasticidade fisiológica entre as espécies utilizadas para os ambientes de menor para maior radiação, concluindo que a amplitude de nicho seja maior.

Scleronema micranthum apresentou alta fragilidade à combinação dos fatores de radiação, entre larguras de linhas com a disponibilidade hídrica, mostrando maior plasticidade morfológica entre as espécies utilizadas. Portanto, a espécie possui características de tolerantes e intolerantes variando pela estação climática.

\section{AGRADECIMENTOS}

À INPA, Cepeam - Associação BSGI e Universidade Soka pelos auxílios concedidos, aos colegas do curso pelo auxílio em algumas coletas e incentivos no trabalho. 


\section{BIBLIOGRAFIA CITADA}

Ackerly, D.D.; Bazzaz, E.A. 1995. Seedling crown orientation and interception of diffuse radiation in tropical forest gaps. Ecology, 76(4): 1134-1146.

Aubréville, A. 1938. La forêt coloniale; les forets d 'Afrique Equatoriale. Bois et Forests des Tropiques, 2: 24-35.

Araújo, V.C. 1970. The factor light as a basic element in tree growth in the Amazonian forest In: Symposium Proceedings on Environment in Amazonia. Manaus. Part I. INPA/NCAR, Manaus, Amazonas. p.67-77.

Arnon, D.I. 1949. Cooper enzymes in isolated chloroplasts. Polyphenoloxidase in Beta vulgaris. Plant Physiology, 24: 1-25.

Bassini, F. 1994. Germinação de Simarouba amara Aubl. (Simaroubaceae), e estabelecimento de plântulas em clareiras naturais e sub-bosque da floresta primária na Amazônia central. Dissertação de Mestrado, Instituto Nacional de Pesquisas da Amazônia/ Fundação Universidade do Amazonas. Manaus, Amazonas. 90pp.

Bazzaz, F.A.; Pickett, S.T.A. 1980. Physiological ecology of tropic; succession: a comparative review. Annual Review of Ecology Systematic, 11: 287-310.

Bazzaz, F.A.; Carlson, R.W.1982. Photosynthetic acclimation to variability in the light environment of early and late successional plants. Oecologia, 54: 313-16.

Bazzaz, F.A.; Wayne, P.M. 1994. Coping with environmental heterogeneity: The physiological ecology of tree seedling regeneration across the gap-understory continuum. In: Caldwell, M.M.; Pearcy, R.W. (Eds). Exploitation of environmental heterogeneity by plants: Ecophysiological processe above-and below ground. Academic Press, San Diego, California, USA. P.349390.

Björkman, O. 1981. Responses to different quantum flux densities. In: Lange, O.L., Nobel, P.S, Osmond, C.B.; Ziegler, H. (Eds). Encyclopedia of Plant Physiology, New Series, Vol.12A. SpringerVerlag, Berlin. p.37-107.

Boardman, N.K. 1977. Comparative photosynthesis of sun and shade plants. Annual Review of Plant Physiology, 28: 355-77.

Bongers, F.; Popma, J. 1988. Response of Cordia megalanthua Blake seedlings to gap environments in tropical rain forest. Functional Ecology, p.379-390.

Bongers, F.; Popma, J. 1990. Leaf dynamics of seedlings of rain forest species in relation to canopy gaps. Oecologia, 82: 122-127.

Brandani, A.; Hartshorn, G.S.; Orians, G.H. 1988. Internal heterogeneity of gaps and species richness in Costa Rican tropical wet forest. Journal of Tropical Ecology, 4: 99-119.

Brown, N.D. 1990. Dipterocarp Regeneration in Tropical Rain Forest Gaps of Different Sizes. D.Phil.thesis, University of Oxford, UK. 169pp.

Brown, N.D. 1993. The implication of climatic and gap microclimate seedling growth conditions in a Bornean lowland rain forest. Journal of Tropical Ecology, 9:153-168.

Brown, N.D.; Whitmore, T.C. 1992. Do dipterocarp seedlings really partition tropical rain forest gaps? Philosophical Transactions Royal Society series B. p.369-78.
Bullock, J.M. 2000. Gaps and Seedling Colonization. In: Fenner, M. (Ed). Seeds: The Ecology of Regeneration in Plant Communities. University of Southampton, UK. 375-395pp.

Catinot, R. 1965. Silviculture tropicale en forêt dense africane. Bois et Forests des Tropiques, 101: 3-16.

Chazdon, R.L.; Fetcher, N. 1984. Photosynthetic light environments in a lowland tropical rain forest of Costa Rica. Journal of Ecology, 72: 553-564.

Chazdon, R.L. 1988. Sunflecks and their importance to forest understory plants. Advances in Ecological Research, 18: 2-54.

Chazdon, R.L.; Pearcy, R.W. 1986. Photosynthetis response to light variation in rainforest species. Oecologia, 69: 524-531.

Clark, D.A.; Clark, D.B. 1984. Spacing dynamics of a tropical rain forest tree: evalution of the Janzen-Connel model. The American Naturalist, 124(6): 769-788.

Cochrane, T.T.; Sánchez, L.G.; Azavedo, L.G.; Porras, J. A.; Garver, C.L. 1984. Land in Tropical América. Vol.3 EMBRAPA-CPAC. p.7-9.

Denslow, J.S. 1980. Gap partitioning among tropical a rainforest trees. Biotropica, 12 (Supplement): 47-55.

Elias, E.M.A. 1997. Estabelecimento de plântulas de Copaifera multijuga Hayne - (CAESALPINIACEAE) em fragmentos florestais e estágios de sucessão. Dissertação de Mestrado, Instituto Nacional de Pesquisas da Amazônia/Fundação Universidade do Amazonas. Manaus, Amazonas. 116 pp.

Engelbrecht, B.M.J.; Wright, S.J.; Steven, D. 2002. Survival and ecophysiology of tree seedlings during El Niño drought in a tropical moist forest in Panama. Journal of Tropical Ecology, 18:569-579.

Field, C.; Mooney, H.A. 1986. The photosynthesis-nitrogen relationship in wild plants. In: Givnish, T.J. (Ed). On the economy of plant form and function. Cambridge University Press, Cambrige. p.25-55.

Givnish, T.J. 1987. Comparative studies of leaf form: Assessing the relative roles of selective pressures and phylogenetic constraints. New Phytologist, 106 (Suppl.): 131-160.

Grubb, P.J. 1977. The maintenance of species-richness in plant communities: The importance of the regeneration niche. Biological Review, 52: 107-145.

Hartshorn, G. 1990. An overview of neotropical forest dynamics. In: Gentry, A.H. (Ed). Four neotropical rainforests. Yale University Press, New Heaven, Connesticut, USA. p.585-599.

Hoflacher, H.; Bauer, H. 1982. Light acclimation in leaves of the juvenile and adult life phases of ivy (Hedera helix). Physiologia Plantarum, 56: 177-182.

Imakawa, A.M. 1996. Ecofisiologia e estabelecimento inicial de Cariniana micrantha Ducke (Lecythidaceae) em uma floresta de terra firme na Amazônia central. Dissertação de Mestrado, Instituto Nacional de Pesquisas da Amazônia/Fundação Universidade do Amazonas. Manaus, Amazonas. 86pp.

INPE, 1997. Climanálise - Boletim de monitoramento e análise climática. Centro de previsão de tempo e estudos climáticos CPTEC. 12(10). 46pp. 
Kwesiga, F.; Grace, J. 1986. The role of the red/ far-red ration in the response of tropical tree seedlings to shade. Annals of Botany, 57: 283-290.

Loach, K. 1970. Shade tolerance in tree seedlings.II. growth analysis of plants raised under artificial shade. New Phytologist, 69: 273286.

Loureiro, A.A.; Silva, M.F.; Alencar, J.C. 1977. Essências Madeireiras da Amazônia. Intituto Nacional de Pesquisas da Amazônia. Manaus, Amazonas. 103 pp.

Montagner, L.H.; Yared, J.A.G. 1982. aspectos da fenologia de Cordia goeldiana Huber e suas relações com alguns parâmetros climáticos. Boletim de pasquisa. No.54. EMBRAPA-CPATUBelém. 18 pp.

Oberbauer, S.F.; Strain. B.R. 1984. Photosyntethsis and successional status of Costa Rican rain forest tree. Photosynthesis Research, 5: 227-232.

Oberbauer, S.F.; Strain, B.R. 1986. Effects of canopy position and irradiance on the leaf physiology and morphology of Pentaclethra macroloba (Mimosaceae). American Journl of Botany, 73(3): 409416.

Oberbauer, S.F.; Clark, D.B.; Clark, D.A.; Rich, P.M.; Vega, G. 1993. Light environment, gas exchange, and annual growth of saplings of three species of rain forest trees in Costa Rica. Journal of Tropical Ecology, 9: 511-523.

Pearcy, R.W. 1989. Radiation and light measurements. In: Pearcy, R.W.; Ehleringer, J.R.; Mooney, H.A.; Rundel, P.W. (Eds). Plant Physiological Ecology: Field methods and instrumentation. Chapman \& Hall, London, p.95-116.

Press, M.C.; Brown, N.D.; Barker, M.G.; Zipperlen, S.W. 1996. Photosynthetic responses to light in tropical rain forest tree seedlings. In: Swaine, M.D. (Ed). The Ecology of Tropical Forest Tree Seedlings. Parthenon Publishing. University of Aberdeen.UK. p.41-57.

Radambrasil. 1978. Levantamento de Recursos Naturais. Vol.17. Folha SB.20, Purus. Rio de Janeiro. 561pp.

Ramos, J.; Grace, J. 1990. The effects of shade on the gas exchange of seedling of four tropical trees from Mexico. Functional ecology, 4: 667-677.

Rego, J.F. 1995. Disperção de sementes e estabelecimento de Cordia bicolor em clareiras naturais. Dissertação de Mestrado. Instituto Nacional de Pesquisas da Amazônia/ Universidade Federal do Amazonas. Manaus, Amazonas. 70pp.

Riddoch, I.; Grace, J.; Fasehun, F.E.; Riddoch, B.; Ladipo, D.O. 1991. Photosynthesis and sucessional status of seedlings in a tropical semi-deciduous rain forest in Nigeria. Journal of Ecology, 79: 491-503

Schulz, J.P. 1960. Ecological studies on rainforest in northern Surinam. Amsterdam. North-Holland, Vol.53(1): 263-267.

Silva, S.E.L.; Canto, A.C. 1994. Comportamento de espécies florestais em povoamento puro na região de Manaus-AM. Rev. UA. Série: Ciências Agrárias, 3: 37-48.
Swaine, M.D.; Whitmore,T.C. 1988. On the defenition of ecological groups in tropical rain forest. Vegetatio, 75: 31-86.

ter Steege, H. 1994. Hemiphot: a Programme to analyze Vegetation Indices, light and light quality from Hemispherical Photographs. The Tropenbos Foundation, Wageningen, The Netherlands. 44pp.

Tomé, J.B. 1997. Manual para interpretação de análise de solo. Editora Agropecuária. Guaíba-Rio Grande do Sul. 247pp.

Thompson, W.A.; Kredemann, P.E.; Craig, I.E. 1992. Photosynthetic response to light and nutrients in sun-tolerant and shade-tolerant rainforest trees. I growth, leaf anatomy and nutrient content. Australian Journal of Plant Physiology, 19: 1-18.

Tilman, D. 1985. The resource ratio hypothesis of succession. American Naturalist, 125: 827-852.

Useche, F.L. 2003. Estabelecimento e desenvolvimento inicial de plântulas de Aniba rosaeodora Ducke em clareiras artificiais. Dissertação de Mestrado. Instituto Nacional de Pesquisas da Amazônia/ Universidade Federal do Amazonas. Manaus, Amazonas. 48pp.

van Dam, O. 2001. Forest filled with gaps. Effects of gap size on water and nutrient cycling in tropical rain forest. A Study in Guyana. Tropenbos-Guyana Series 10. Georgetown, Guyana.

Vieira, G. 1987. Análise estrutural da regressão natural, após diferentes niveis de exploração em uma floresta tropical úmida. Dissertação de Mestrado. Instituto Nacional de Pesquisas da Amazônia/ Fundação Universidade do Amazonas. Manaus, Amazonas. $164 \mathrm{pp}$.

Vieira, G. 1996. Gap dynamics in managed Amazonian forest: structural and ecophysiological aspects. Tese de Doutrado. Universidade de Oxford, UK. 161pp.

Whathey, J.M.; Whatley, F.R. 1982. A luz e a vida das plantas. Tema de Biologia, 30. EPU-EDUSP, São Paulo. 101pp.

Wayne, P.M.; Bazzaz, F.A. 1993. Morning vs afternoon sun patches in experimental forest gaps: sequences of temporal incongruency resources to birch regeneration. Oecologia, 94: 235-243.

Weis, E.; Berry, J.A. 1988. Plants and high temperature stress. In: Long, S.P.; Woodward, F.I. (Eds). Plants and Temperature. Symposium of the society of experimental biology. No.42. Company of Biologists Ltd., Cambridge. P.329-346.

Whitmore, T.C. 1990. An introduction to tropical rain forest. Oxford University New York. 226pp.

Yano, C.Y. 1998. Efeitos da liteira fina sobre a disponibilidade de nutrientes e o crescimento de plântulas em áreas de extração seletiva de madeira. Relatório apresentado ao CNPq. Manaus, Amazonas. 19 pp.

Yared, J.A.G. 1985. Resultados de pesquisa da EMBRAPA/IBDF-PNPF sobre espécies nativas da Amazônia. EMBRAPA-CPATU.Belém, Pará. 32 pp.

Recebido em 20/10/2004

Aceito em 11/04/2006 